\title{
Control Design for a Generic Commercial Aircraft Engine
}

Jeffrey Csank

N\&R Engineering and Management Services, Cleveland, Ohio

Ryan D. May

ASRC Aerospace Corporation, Cleveland, Ohio

Jonathan S. Litt and Ten-Huei Guo

Glenn Research Center, Cleveland, Ohio 


\section{NASA STI Program . . . in Profile}

Since its founding, NASA has been dedicated to the advancement of aeronautics and space science. The NASA Scientific and Technical Information (STI) program plays a key part in helping NASA maintain this important role.

The NASA STI Program operates under the auspices of the Agency Chief Information Officer. It collects, organizes, provides for archiving, and disseminates NASA's STI. The NASA STI program provides access to the NASA Aeronautics and Space Database and its public interface, the NASA Technical Reports Server, thus providing one of the largest collections of aeronautical and space science STI in the world. Results are published in both non-NASA channels and by NASA in the NASA STI Report Series, which includes the following report types:

- TECHNICAL PUBLICATION. Reports of completed research or a major significant phase of research that present the results of NASA programs and include extensive data or theoretical analysis. Includes compilations of significant scientific and technical data and information deemed to be of continuing reference value. NASA counterpart of peer-reviewed formal professional papers but has less stringent limitations on manuscript length and extent of graphic presentations.

- TECHNICAL MEMORANDUM. Scientific and technical findings that are preliminary or of specialized interest, e.g., quick release reports, working papers, and bibliographies that contain minimal annotation. Does not contain extensive analysis.

- CONTRACTOR REPORT. Scientific and technical findings by NASA-sponsored contractors and grantees.
- CONFERENCE PUBLICATION. Collected papers from scientific and technical conferences, symposia, seminars, or other meetings sponsored or cosponsored by NASA.

- SPECIAL PUBLICATION. Scientific, technical, or historical information from NASA programs, projects, and missions, often concerned with subjects having substantial public interest.

- TECHNICAL TRANSLATION. Englishlanguage translations of foreign scientific and technical material pertinent to NASA's mission.

Specialized services also include creating custom thesauri, building customized databases, organizing and publishing research results.

For more information about the NASA STI program, see the following:

- Access the NASA STI program home page at http://www.sti.nasa.gov

- E-mail your question via the Internet to help@ sti.nasa.gov

- Fax your question to the NASA STI Help Desk at 443-757-5803

- Telephone the NASA STI Help Desk at 443-757-5802

- Write to: NASA Center for AeroSpace Information (CASI) 7115 Standard Drive Hanover, MD 21076-1320 


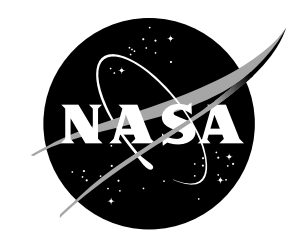

\section{Control Design for a Generic Commercial Aircraft Engine}

Jeffrey Csank

N\&R Engineering and Management Services, Cleveland, Ohio

Ryan D. May

ASRC Aerospace Corporation, Cleveland, Ohio

Jonathan S. Litt and Ten-Huei Guo

Glenn Research Center, Cleveland, Ohio

Prepared for the

46th Joint Propulsion Conference and Exhibit

cosponsored by the AIAA, ASME, SAE, and ASEE

Nashville, Tennessee, July 25-28, 2010

National Aeronautics and

Space Administration

Glenn Research Center

Cleveland, Ohio 44135 


\section{Acknowledgments}

The authors would like to thank Juan Marcos and James Fuller at Pratt \& Whitney, who reviewed the baseline controller architecture and provided guidance to ensure that a realistic simulation was developed. Our thanks also go to Diana Drury of ASRC Aerospace, Corp., who handled the version control system for C-MAPSS40k. Finally, our thanks go to the NASA Aviation Safety Program's Integrated Resilient Aircraft Control Project for funding this work.

Trade names and trademarks are used in this report for identification only. Their usage does not constitute an official endorsement, either expressed or implied, by the National Aeronautics and Space Administration.

Level of Review: This material has been technically reviewed by technical management.

Available from

NASA Center for Aerospace Information 7115 Standard Drive

Hanover, MD 21076-1320
National Technical Information Service 5301 Shawnee Road Alexandria, VA 22312

Available electronically at http://gltrs.grc.nasa.gov 


\title{
Control Design for a Generic Commercial Aircraft Engine
}

\author{
Jeffrey Csank \\ N\&R Engineering and Management Services \\ Cleveland, Ohio 44130 \\ Ryan D. May \\ ASRC Aerospace Corporation \\ Cleveland, Ohio 44135 \\ Jonathan S. Litt and Ten-Huei Guo \\ National Aeronautics and Space Administration \\ Glenn Research Center \\ Cleveland, Ohio 44135
}

\begin{abstract}
This paper describes the control algorithms and control design process for a generic commercial aircraft engine simulation of a 40,000 $\mathrm{lb}$ thrust class, two spool, high bypass ratio turbofan engine. The aircraft engine is a complex nonlinear system designed to operate over an extreme range of environmental conditions, at temperatures from approximately -60 to $120+{ }^{\circ} \mathrm{F}$, and at altitudes from below sea level to $40,000 \mathrm{ft}$, posing multiple control design constraints. The objective of this paper is to provide the reader an overview of the control design process, design considerations, and justifications as to why the particular architecture and limits have been chosen. The controller architecture contains a gain-scheduled Proportional Integral controller along with logic to protect the aircraft engine from exceeding any limits. Simulation results illustrate that the closed loop system meets the Federal Aviation Administration's thrust response requirements.
\end{abstract}

\section{Nomenclature}

$\begin{array}{ll}\text { Alt } & \text { Altitude (ft) } \\ E P R & \text { Engine Pressure Ratio } \\ \text { FAA } & \text { Federal Aviation Administration } \\ F B & \text { Integral gain multiplier based on current power level } \\ \text { HPC } & \text { High Pressure Compressor } \\ I F B & \text { Integral Feedback Gain } \\ I W U P & \text { Integral Wind-Up Protection } \\ K i & \text { Integral Gain } \\ K p & \text { Proportional Gain } \\ \text { LPC } & \text { Low Pressure Compressor } \\ \text { LPT } & \text { Low Pressure Turbine } \\ M A X & \text { Maximum function } \\ M I N & \text { Minimum function } \\ \text { Mn } & \text { Mach Number } \\ N & \text { Rotor Speed (either core of fan) } \\ N d o t & \text { Rotor Acceleration } \\ N c & \text { Core Speed } \\ N f & \text { Fan Speed } \\ P I & \text { Proportional plus Integral (control) } \\ P s 3 & \text { High Pressure Compressor Discharge Static Pressure (psi) }\end{array}$


P2 Inlet Pressure (Pressure at Station 2.0)

P50 Low Pressure Turbine Discharge Pressure (psi)

$R U \quad$ Ratio Unit (Wf/Ps3)

SLS Sea Level Static: environmental condition defined as an altitude of $0 \mathrm{ft}$ and Mach number 0.0

T30 High Pressure Compressor Discharge Temperature $\left({ }^{\circ} \mathrm{R}\right)$

T40 High Pressure Turbine Inlet Temperature $\left({ }^{\circ} \mathrm{R}\right)$

Wf Fuel flow rate $(\mathrm{lb}-\mathrm{m} / \mathrm{sec})$

Wf Cmd Fuel flow rate (lb-m/sec) command to the fuel metering valve

Wf Reg Desired Fuel flow rate $(\mathrm{lb}-\mathrm{m} / \mathrm{sec})$ computed by a regulator

\subsection{Introduction}

The work described in this paper represents a complete algorithmic-level control design for a generic, commercial, high-bypass turbofan engine simulation. The controller architecture and algorithms are illustrative of those used on commercial turbofan engines today. Several descriptions of the basic control structure for modern commercial aircraft engines exist in the literature (Refs. 1 to 5), but none of these goes through the actual control design process. This paper leads the reader through the process in detail, describing various considerations and guidelines in general terms, and also describing the development and integration of controller components. The generic engine model used is the Commercial Modular Aero-Propulsion System Simulation 40K (C-MAPSS40k), a full envelope, nonlinear, physics-based model. The simulation's behavior is accurate enough over the frequencies of interest to provide a realistic control design problem, requiring the designer to account for a wide range of operating conditions, constraints, and performance objectives similar to those in a control design for a real commercial turbofan engine.

C-MAPSS40k is a 40,000 lb thrust class, two spool, physics-based, component level, high bypass turbofan engine simulation and closed loop controller written in the MATLAB/Simulink (The MathWorks, Inc.) environment (Ref. 6). Each of the aircraft engine's turbomachinery components-fan tip, fan hub with low pressure compressor (LPC), high pressure compressor (HPC), high pressure turbine, and low pressure turbine (LPT) - is represented as a single lumped volume. The system has two state variables, fan speed and core speed. This modeling approach captures the dominant engine dynamics necessary for control design purposes. Volume dynamics, which are faster, are not captured by this model. Included in the engine simulation are models of the actuators (fuel metering valve, variable stator vane, and variable bleed valve) and sensors. This paper discusses the control algorithm design process for the C-MAPSS40k engine, as well as some of the challenges associated with aircraft engine control in general. The C-MAPSS40k controller is a digital controller with a default sampling time of $0.015 \mathrm{sec}$, and is representative of a generic commercial aircraft engine controller. A major challenge in aircraft engine control design is that the engine must operate reliably over an extended range of environmental conditions, defined by altitude, Mach number, and temperature. The C-MAPSS40k engine has an altitude range of $-2,000$ to $40,000 \mathrm{ft}$, Mach number range of 0.0 to 0.8 , and an ambient temperature range from -30 to $+50{ }^{\circ} \mathrm{F}$ from the standard day temperature at the operating altitude. The control design process for this type of system is complex due to nonlinearities, performance constraints, and physical and safety limits that must be met.

The aircraft engine control system has three main functions: 1) to maintain thrust at a specified level for a given throttle position, 2) to provide good performance when transitioning between demanded thrust levels, and 3) to ensure safe operation. The accomplishment of the latter two functions is complicated by the fact that the engine frequently operates at or near an engine limit during very large throttle transients and at high power settings (Refs. 1 and 2). The first two functions control the power level at which the engine operates; this is referred to as power management. The last function protects the engine from exceeding its physical or safety limits; this is referred to as protection logic. Thus the engine controller logic can be divided into two parts: power management and protection logic. The remainder of this paper 
expands on these topics in general while describing the specific control design for the C-MAPSS40k engine simulation.

The paper is organized as follows: Section 2.0 poses the control problem; Section 3.0 discusses power management control; Section 4.0 addresses protection logic; and Section 5.0 covers the controller architecture, specifically techniques to integrate the power management with the protection logic. Section 6.0 discusses an integral wind-up protection scheme and Section 7.0 contains an example closed loop simulation.

\subsection{Problem Description}

A typical closed loop control system for an aircraft engine is shown in Figure 1. The pilot commands a thrust level via the throttle in the cockpit, which is converted to a measurable setpoint, commonly either Engine Pressure Ratio $(E P R)$ or fan speed $(N f)$, which is based on the flight condition. Thrust is not used as the setpoint since thrust is not measurable. The difference between the setpoint and the feedback produces an error, which is the input to the setpoint controller. The setpoint controller responds to this error by commanding a fuel flow rate, which is passed to the protection logic controller. The protection logic then either passes it through to the fuel metering valve actuator, or determines a fuel flow rate command that will result in safe engine operation. The actuator delivers the fuel to the engine where it is burned to drive the turbines and connected compressors. This action forces air through engine to produce thrust.

An aircraft engine controller has to satisfy two types of requirements: performance and safety. Performance requirements are different for small throttle transients and steady-state operation than for large transients. For small throttle transients, the closed-loop system should have specific frequency response characteristics as discussed in Section 3.3. The performance requirements for large throttle transients are based on the time it takes to bring the engine from idle to full power and are fully described in Federal Aviation Administration (FAA) regulations as discussed in Section 7.0. The safety or operability requirements of the controller are to ensure that the engine does not operate in a manner that

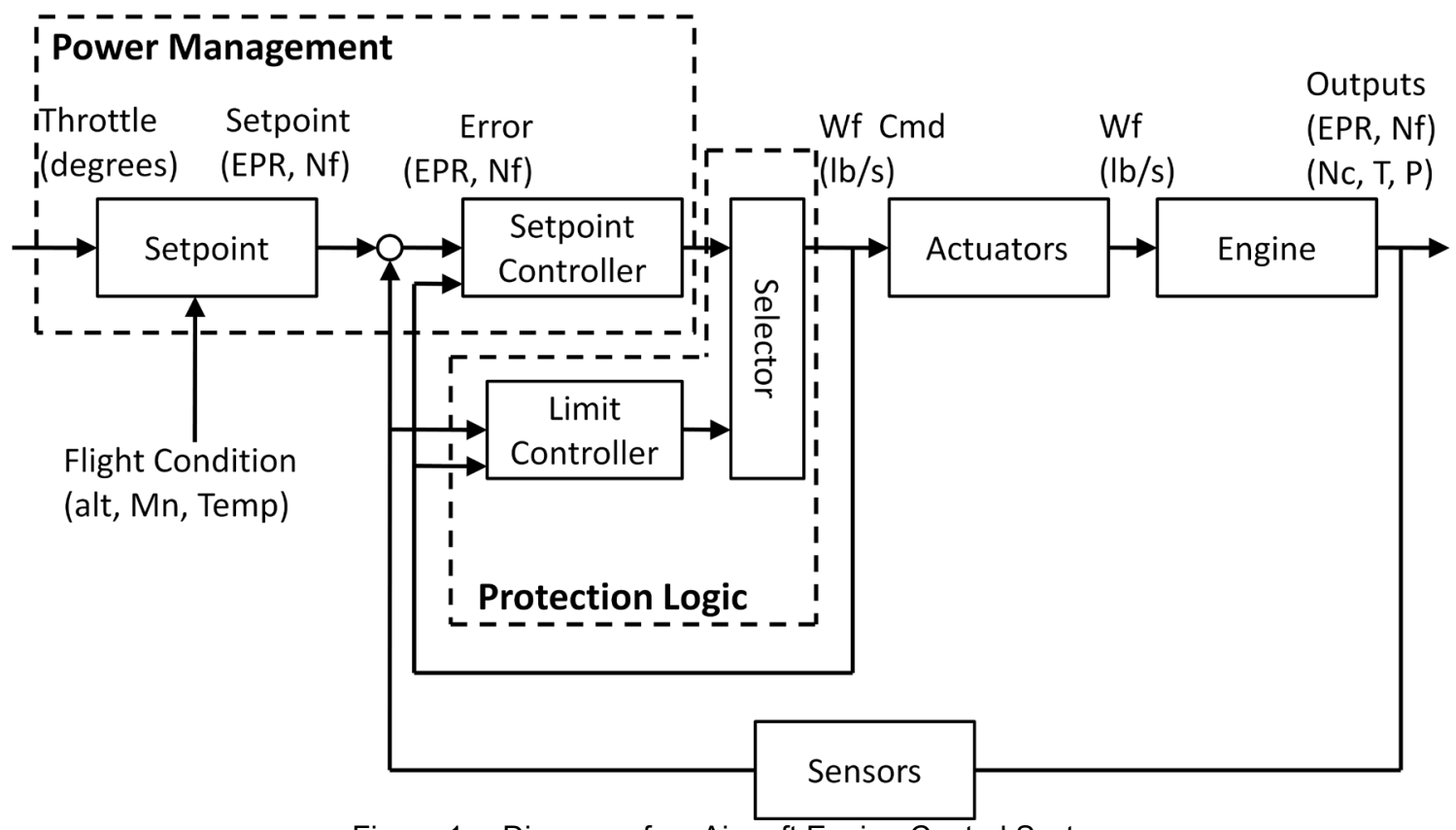

Figure 1.-Diagram of an Aircraft Engine Control System. 
will cause it to stall or that its components will experience excessively life-shortening or damaging stresses. Of specific concern in commercial aircraft engines are compressor stalls or surges, overpressurization of the combustor, rotor over-speed, and flame-out of the combustor. These safety requirements are discussed in the various topics in Section 4.0.

\subsection{Power Management Control}

The main purpose of the power management controller is to operate the engine at the specified power level requested by the pilot via the throttle input. This type of controller is also referred to as a setpoint controller (Ref. 1). This controller regulates the system as the controlled variable reaches its setpoint and tracks small changes in the setpoint.

\subsection{Controlled Variables}

The controlled variable is a sensed system output that is to be controlled. For aircraft engines, the ideal controlled variable would be thrust, since the throttle input corresponds to a demanded thrust level. Thrust is not measurable during flight but is proportional to the airflow through the engine, allowing other engine outputs to be used to control thrust indirectly (Figure 2 shows C-MAPSS40k with the variables of interest labeled). The Engine Pressure Ratio $(E P R)$, which is the low pressure turbine discharge pressure (P50 shown in Figure 2) divided by the inlet pressure $(P 2)$, correlates well with the airflow through the engine and thus is a good variable to use to regulate thrust (Ref. 3). Other options for the control variables are fan speed (Nf) or core speed $(N c)$, both of which are shown in Figure 2. Fan speed correlates better with thrust than core speed does, since the fan handles all of the airflow that produces thrust, both bypass flow and core flow, while the core speed only varies with the airflow through the core. Both EPR and fan speed have proven effective as engine control variables (Ref. 3) and either can be selected as the controlled variable in C-MAPSS40k.

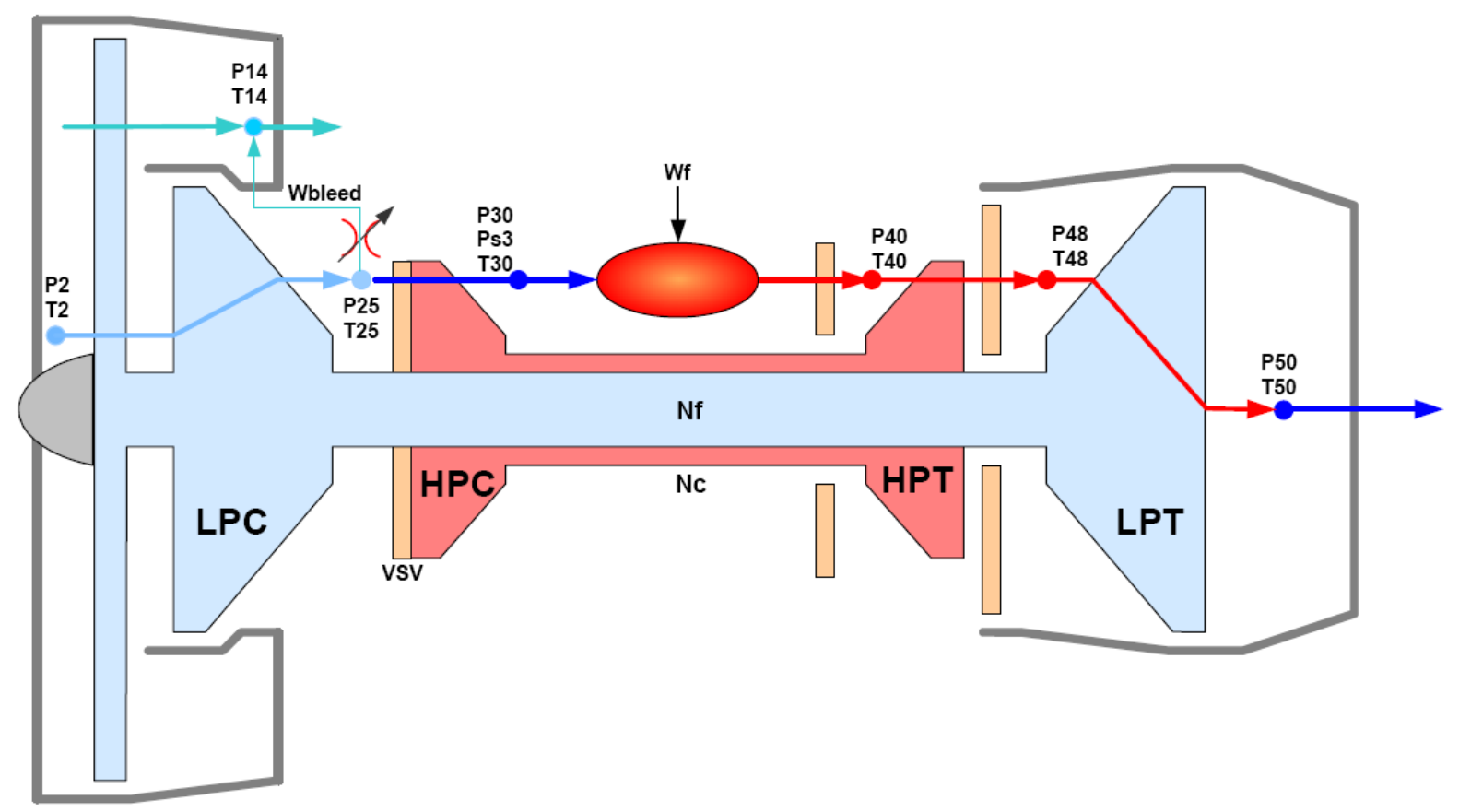

Figure 2.-Diagram of the C-MAPSS40k Engine. 


\subsection{Setpoints}

The design goal of the setpoint specification is to produce thrust as a linear function of throttle position at any environmental condition, as well as produce the requested thrust (such as take-off thrust, flight idle, max power, cruise power, etc.) independent of the environmental condition (Ref. 3). The actual setpoint value is determined from the throttle position and is in terms of either EPR or $N f$. The required take-off thrust is different at Sea Level than at 5,000 ft; regardless, when the pilot moves the throttle to the take-off thrust position, the corresponding setpoint must produce the required thrust for take-off at that environmental condition.

The desired SLS thrust profile, defined by steady-state values of thrust versus throttle position, is created by determining the full power thrust, take-off thrust, cruise thrust, flight idle thrust, and an appropriate ground idle thrust at $S L S$ conditions. The desired thrust values for intermediate throttle inputs are determined through linear interpolation based on the finite number points that define the setpoint curve. The thrust profile at other environmental conditions is developed by scaling the SLS thrust profile at different environmental conditions. The setpoints for C-MAPSS40k were designed by adjusting the fuel flow input into the open-loop engine until the net thrust produced by the open loop C-MAPSS40k engine matched the desired thrust for the particular throttle setting. The measured EPR or $N f$ at this condition was used as the corresponding setpoint for the specified environmental condition and throttle input. The process of matching the thrust profile was repeated across the range of C-MAPSS40k environmental operating conditions. Figure 3 shows the EPR setpoint curve for the SLS operating condition; the corresponding net thrust is also included to show the correlation.

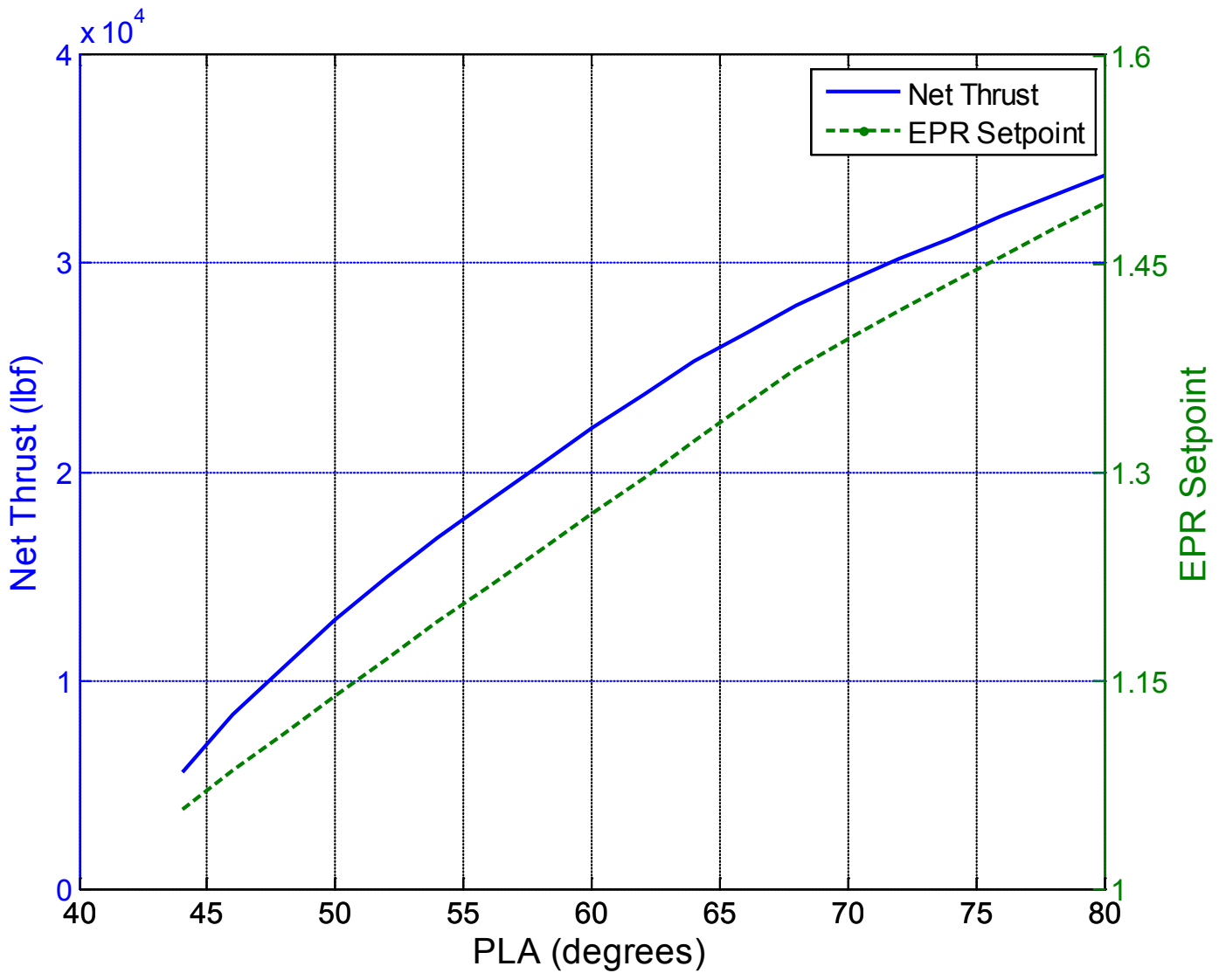

Figure 3.-Net Thrust and EPR Setpoint Curve for C-MAPSS40k at SLS Condition. 


\subsection{Control Requirements}

The power management controller requirements may be stated in the frequency domain in terms of gain margin, phase margin, and bandwidth. All three of these characteristics can be determined by generating a Bode plot of the loop gain. The loop gain is the product of the controller transfer function and the open loop engine transfer function (including sensor and actuator dynamics) at a specified flight condition; the specific details of this process can be found in any introductory linear systems textbook such as Reference 7. From Reference 1, the gain margin should be greater than $6 \mathrm{~dB}$ and the phase margin should be greater than $45^{\circ}$. For C-MAPSS40k, the controller was designed to achieve high bandwidth with a constraint of producing a gain margin of at least $6 \mathrm{~dB}$, a phase margin greater than $45^{\circ}$, and a critically damped closed-loop response.

\subsection{Setpoint Controller}

A block diagram of the C-MAPSS40k setpoint controller, which is designed to control either EPR or $N f$, is shown in Figure 4. A Proportional-Integral $(P I)$ controller is used and the gains ( $K p$ and $K i$, respectively) are scheduled based on altitude and Mach number. Gain scheduling will be discussed in Section 3.5. There is an additional gain before the integrator $(F B)$ that is scheduled based on the altitude and the power level (pwr in Figure 4); this aids in producing a critically damped response at different power levels. The EPR controller features a low-pass filter for the setpoint error. This filter serves to remove the high frequency components of the error signal, which are not found in the fan speed error signal. The integrator term contains an Integral Wind-Up Protection (IWUP) scheme that includes the gain IFB, which will be discussed in Section 6.0. The output of the controller, Wf Reg, is the controller's desired fuel flow rate. $W f C m d$ is the actual fuel flow rate at the last time step, or update, and will be discussed in Section 6.0.

\subsection{Gain Scheduling}

The aircraft engine has to operate over a wide range of environmental conditions. The fact that the engine behaves differently at different environmental conditions adds to the complexity of the control design. One way of handling this complexity is to use gain scheduling, which takes advantage of interpolation.

The main idea of gain scheduling is to break a large, complex, non-linear system into a collection of range-limited linear systems, or subsystems. The ranges of these subsystems are defined by break points, which are specific values of some internal or external variables such as fan speed, core speed, altitude, etc. The selection of the breakpoints is critical, since the system behavior between adjacent breakpoints is

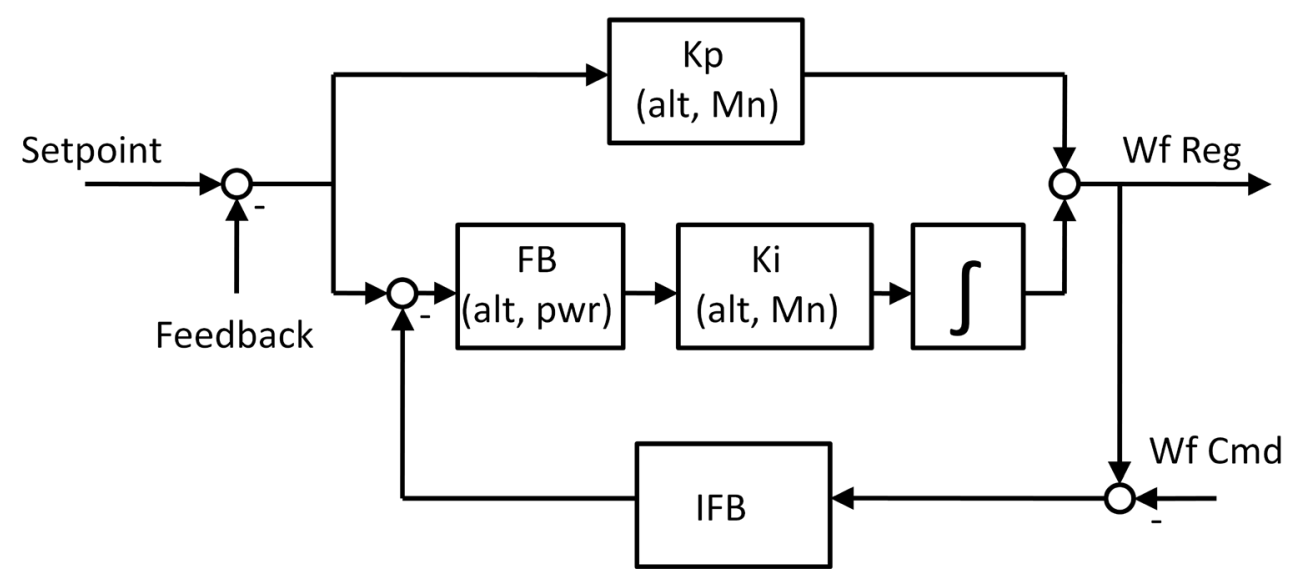

Figure 4.-C-MAPSS40k Setpoint Controller Structure. 
assumed to be linear to allow for the use of linear interpolation between the subsystems. The controller is then tuned at each breakpoint. This allows a set of linear controllers to be used to control a highly nonlinear system. During operation, the breakpoint values are used to determine the value of the controller gains at each time step by interpolating between the nearest defined subsystems. Figure 5 shows the flight envelope for the C-MAPSS40k engine and the breakpoints chosen for the C-MAPSS40k PI controller gains. When the engine is at flight condition 1, shown in Figure 5, the PI gains at breakpoints $\mathrm{A}, \mathrm{B}, \mathrm{C}$, and $\mathrm{D}$ are used by a linear interpolation algorithm to determine the $P I$ gain that should be used by the controller at flight condition 1 . The interpolation schemes become more complex as the number of scheduling variables increases.

\subsection{Protection Logic Control}

The power management controller operates the engine at the requested power level and for changes in the requested power level. For large throttle transients, the power management controller only regulates the controlled variable, while additional logic, or limiters, are used to protect critical engine variables from exceeding physical bounds and to ensure safe operation (Ref. 3). The limiters in the C-MAPSS40k

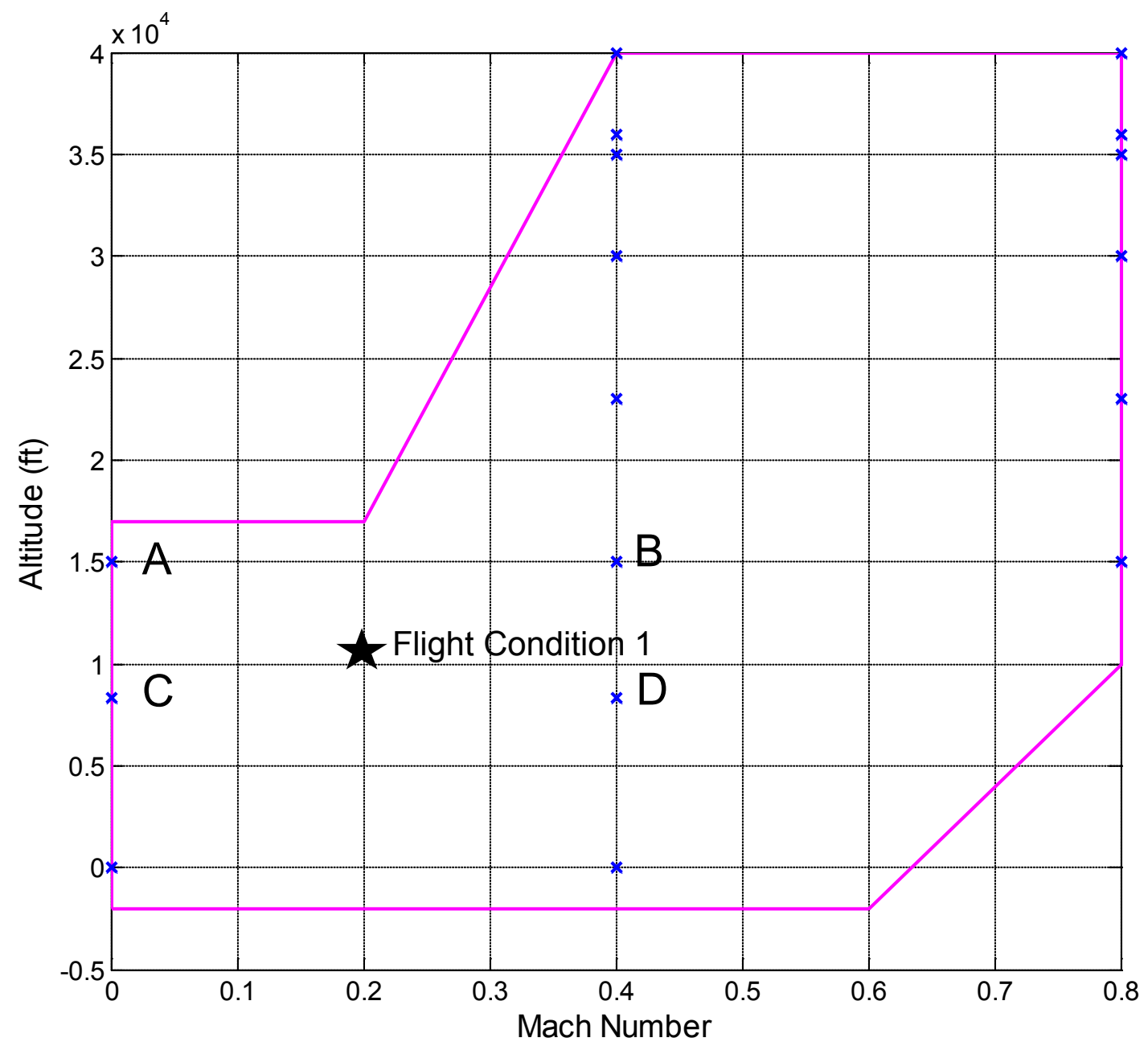

Figure 5.-Locations of the Breakpoints Chosen for the EPR Setpoint Controller (blue "x"s) and the C-MAPSS40k Flight Envelope (magenta line). 
controller restrict shaft speeds, combustor pressure, engine acceleration, and minimum ratio unit, which is the fuel flow rate divided by the high pressure compressor discharge static pressure (Wf/Ps3). The maximum speed and maximum combustor pressure limiters protect mechanical limits, while the acceleration schedule, minimum combustor pressure limit, and minimum ratio unit limiter ensure safe and stable operation (Ref. 4). The protection logic is designed to produce critically damped responses, and to ensure that critical variables do not exceed their limits. In C-MAPSS40k, each limit regulator is implemented as a PI controller, similar to the setpoint controller shown in Figure 4. The main difference here is that there is no feedback gain (FB) and the PI gains are constant, not scheduled. The following subsections will discuss each of the individual limiters and their implementation.

\subsection{Maximum Speed Limiters}

The maximum speed limiters protect both the fan and core shafts from excessive speed that could cause a disk to burst or blade failure. The fan shaft may be driven to exceed its limit due to an off-design mismatch of the fan and core shaft speeds, usually due to either deterioration or damage (Ref. 2). The core shaft may exceed its limit when the fan shaft is driven into over-speed, the fuel metering valve fails open, or a speed sensor fails, resulting in excessive fuel flow to the engine (Ref. 2).

The C-MAPSS40k maximum speeds were determined by testing various engine operating points to find the flight condition that requires the highest rotor speed at normal operation in the flight envelope on a standard day: 15,000 ft, $0.85 \mathrm{Mach}$, standard day temperature, at full power. The maximum speed limit is then set to 110 percent of the measured shaft speeds at that condition. For a real engine, these limits would be based on the physical properties of the engine components. A block diagram of the max fan speed limiter architecture is shown in Figure 10 of the Appendix. The max core speed limiter architecture is the same as that for fan speed, shown in Figure 10.

\subsection{Combustor Pressure Limiters (Ps3 Minimum and Maximum)}

The combustor pressure limiter consists of a minimum and maximum limit, determined from measuring the high pressure compressor discharge static pressure, which is the input to the combustor. The upper limit is a physical limit and protects against exceeding the maximum combustor casing pressure limit (Ref. 4). This condition can be caused by over-speed or by the inlet total pressure, $P 2$ (Figure 2), exceeding its physical limit (Ref. 1). The Ps3 lower limiter serves to maintain stable engine operation at idle power.

The maximum Ps 3 limit in C-MAPSS40k was determined by simulating the flight condition that produces the greatest combustor pressure in the flight envelope, at any temperature: $2,000 \mathrm{ft}$ below sea level, $0.5 \mathrm{Mach}$, and a delta ambient temperature of $-30^{\circ} \mathrm{F}$. The lower limit was determined by simulating a minimum idle condition and ensuring a stable, steady response in the system at the full range of operational altitudes. Additionally, the lower limit is adjusted based on the engine operational inputs, such as the customer bleed, additional power extraction, and whether the aircraft is on the ground or in flight. When there is a demand to divert some of the engine's airflow to power the aircraft's systems (this diverted airflow is known as customer bleed), the limit is increased to account for the extra power required to generate the bleed flow specified. The actual limit value is different for ground idle and flight idle operation (Ref. 1). The max Ps3 limiter architecture is the same as that shown in Figure 10 of the Appendix. The min Ps 3 limiter architecture is shown in Figure 11 of the Appendix.

\subsection{Acceleration Limiter}

The purpose of the acceleration limiter is to prevent high pressure compressor stall during quick accelerations or large changes in thrust demand. A rapid acceleration will cause the HPC operation to approach stall. For C-MAPSS40k controller design, an acceleration schedule was selected to allow even a 
deteriorated engine to meet the necessary performance requirements while still ensuring an acceptable stall margin (Ref. 2). Reference 3 suggests four potential representations for an acceleration schedule:

1. Fuel Flow ( $W f$ ) versus Rotor Speed (N)

2. Fuel Flow ( $W f) /$ Compressor Discharge Static Pressure (Ps3) versus Rotor Speed

3. HPC exit temperature (T30) versus Core Rotor Speed

4. Rotor Acceleration (Ndot) versus Rotor Speed

The acceleration schedule implemented in the baseline controller of C-MAPSS40k was designed using core acceleration ( $N c d o t$ ) versus corrected core speed $(N c)$, and is plotted in Figure 6 . Thus, during transients, the engine core is controlled to accelerate along a schedule that is a function of the current core speed. The acceleration schedule was determined by running a large transient at sea level static conditions and modifying the schedule until an acceptable stall margin was maintained, even for the fully deteriorated engine. A range of environmental conditions was then tested to ensure that the acceleration limiter was designed correctly and provides ample HPC stall margin over all operational conditions. A block diagram of the Acceleration limiter architecture is shown in Figure 12 of the Appendix.

\subsection{Ratio Unit Limiter (Wf/Ps3)}

The Ratio Unit $(R U)$ limiter provides good control of high pressure turbine inlet temperature (T40), compressor stall, and protection against combustor blow out (Ref. 3). This limiter can serve as both a minimum limit, protecting against LPC stall on decelerations and combustor lean blow out, and as a maximum limit, protecting against HPC stall (Refs. 4 and 5).

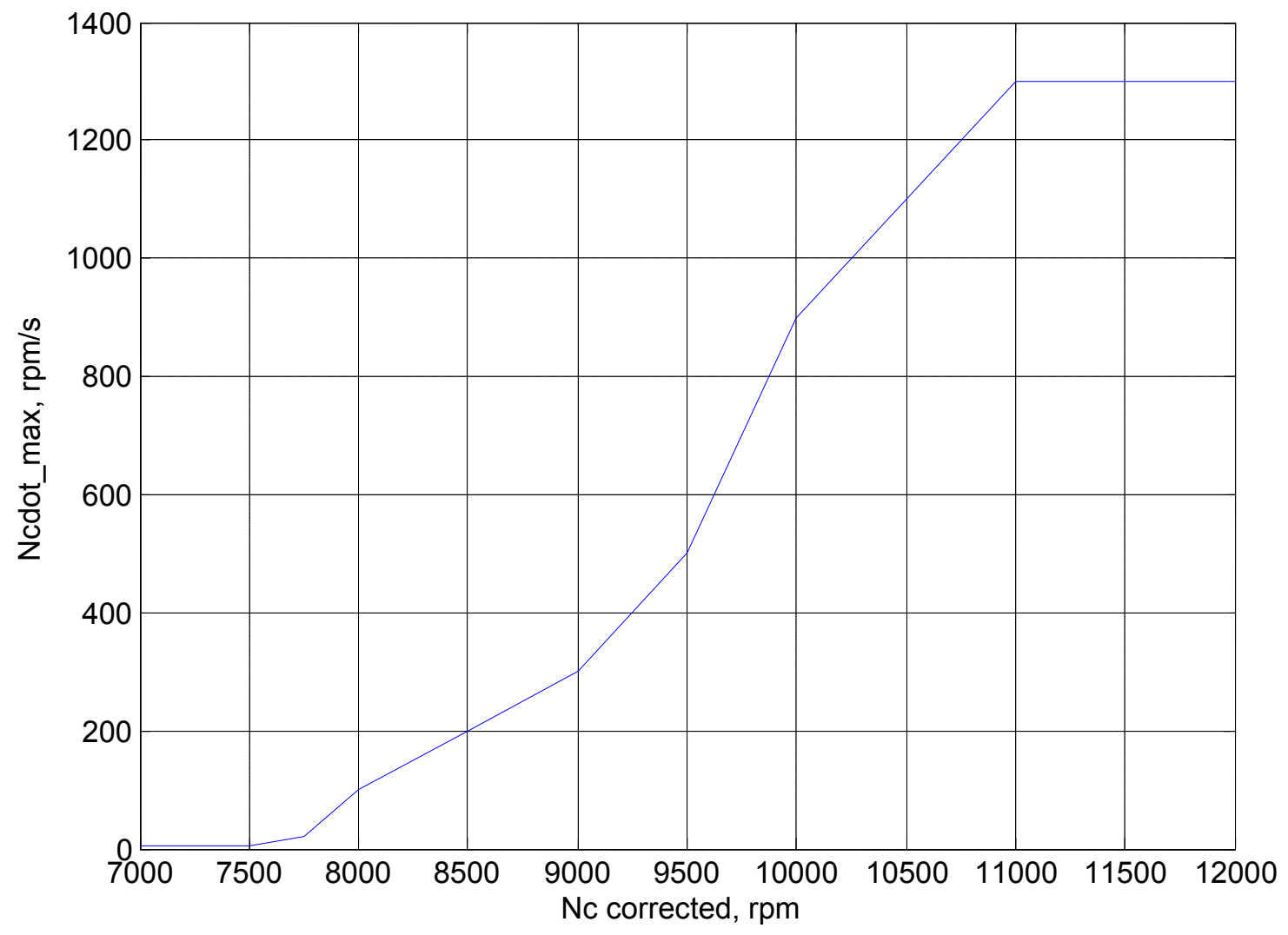

Figure 6.-The Acceleration Schedule Implemented in C-MAPSS40k. 
C-MAPSS40k features a minimum $R U$ limit only as HPC stall is protected by the acceleration limiter described above. It was found that in C-MAPSS40k, designing the limiter to prevent blow out also ensured adequate LPC stall margin during decelerations. A block diagram of the $R U$ min limiter architecture is shown in Figure 13 of the Appendix.

\subsection{Controller Architecture}

The successful operation of an aircraft engine depends on coordination between the power management (which operates the engine at the desired power level) and protection logic (which protects the engine from exceeding its physical and safety limits). Therefore, it is critical to select a control architecture that will effectively switch between the power management controller and the protection logic controller and provide a smooth fuel flow command signal to the engine's fuel metering valve. A control architecture commonly used in commercial engines is a MIN-MAX structure (Refs. 1, 3, and 4). shown in Figure 7.

The control architecture is designed to operate the engine in a conservative way, i.e., to drive the engine to the setpoint specified by the throttle without exceeding any limits. The power management controller determines the fuel flow required to drive the engine to its setpoint or maintain the setpoint. Each limit controller determines the fuel flow necessary to drive the engine to its individual limit without overshoot, or maintain the limit. Thus the protection logic acts to constrain the transient to guarantee safe operation.

First, consider only the protection logic, the max limiters and min limiters shown in Figure 7. The $M I N-M A X$ structure is designed to maintain critical engine variables within limits. This is achieved by comparing the outputs of the limit controllers and selecting the one that will ensure that no limit is exceeded. First, the outputs of all of the max limiters, $N f$ Max, $N c$ Max, Ps 3 Max, and the Acceleration Schedule, are compared by the MIN selector. The minimum fuel flow command is selected since it corresponds to the limiter that is closest to its limit. This ensures that if the closest limit is reached, no other maximum limit is exceeded. Next, the outputs of the min limiters are compared. In this case, the maximum signal is selected since the largest signal ensures that none of the lower limits is exceeded. In

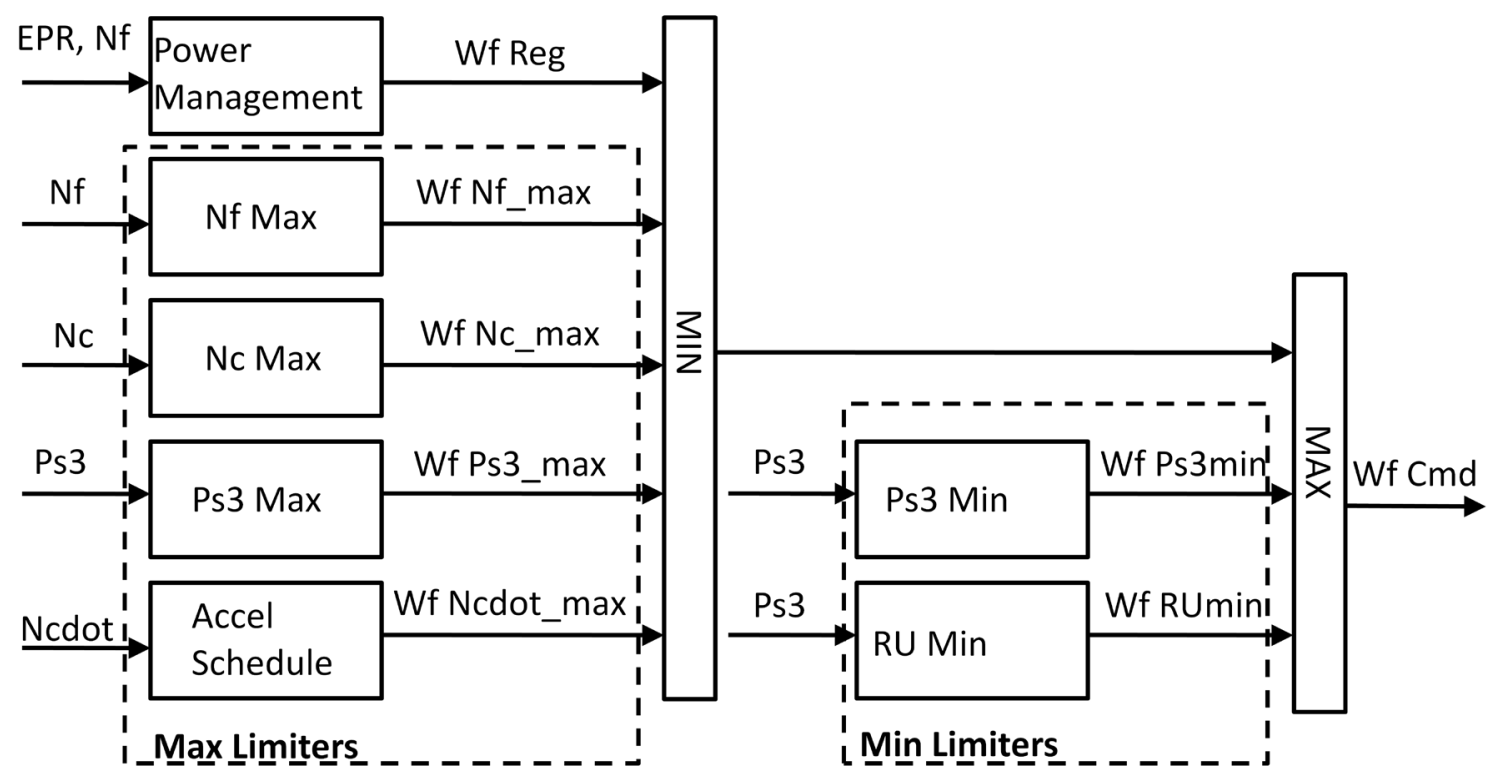

Figure 7.-C-MAPSS40k MIN-MAX Controller Architecture, showing the integration of the Protection Logic Controller (Max Limiters and Min Limiters) and the Power Management Controller. 
Figure 7, the $M A X$ selector block has three inputs: the output from the $M I N$ selector, $P s 3$ Min, and $W f / P s 3$ Min. The controller that generates the fuel flow command selected by the $M A X$ selector block becomes the active controller.

The protection logic sets the upper and lower bounds on engine operation. However, within the range of unrestricted operation, the power management controller is active. As shown in Figure 7, the power management controller is also included in the MIN-MAX scheme. When the engine is operating near a desired setpoint and not near a limit, the power management controller should produce a command signal that is smaller than that produced by any of the max limiters, and larger than that produced by any of the min limiters. This is due to the fact that the error between the desired operating condition and the current engine condition is smaller in magnitude than the errors between the engine limits and current condition. Therefore, adding the power management controller to the $M I N$ selector will allow the output to be compared to both the max and min limiters and satisfy both sets of constraints. The final controller architecture is shown in Figure 7, where $\mathrm{WfCmd}$ is the fuel flow rate command provided to the fuel metering valve.

\subsection{Integral Wind-Up Protection}

The C-MAPSS40k simulation uses Proportional Integral $(P I)$ controllers for the power management controllers and the limit controllers, a total of seven controllers. It is desirable to have integral action in the controller since the presence of an integral term eliminates steady state error in the controlled variable. Consider the PI control law:

$$
u(t)=K_{p} e(t)+K_{i} \int e(t) d t
$$

where $K_{p}$ is the proportional gain, $K_{i}$ is the integral gain, and $e(t)$ is the error at time $t$. For each individual controller in the MIN-MAX structure, an error is produced that the control law tries to drive to zero; for example the $N f$ Max controller is designed to drive the fan speed to $N f$ Max. However, only one controller may be active at any time, and for each of those not selected by the MIN-MAX strategy, the error between the desired and actual variable value will remain nonzero. This error is continuously integrated by the individual controller's integral term, and the integral increases in magnitude since, when the controller is not active, the variable does not reach its setpoint. This phenomenon is known as integral wind-up. Because of this, Integral Wind-Up Protection $(I W U P)$ is used to reduce the effect of the integral term in each non-selected $P I$ controller.

One possible protection scheme, presented in Reference 1, is to multiply the error seen by the integrator by zero when the individual controller is not active, thus ensuring that there is not an increase in the magnitude of the integral term's output. The problem with this approach is that when that controller becomes active there may be a step-change in the fuel flow rate command. Furthermore, if the integral term is held at zero or some other small value, once that controller is activated it will take a significant amount of time for the integral term to be able to exert effective control effort, resulting in an unnecessarily slow transient response.

An alternate approach to IWUP from Reference 8 was adopted for C-MAPSS40k; it is shown in Figure 4. The main idea with this approach is to decrease the error seen by the integrator of the inactive controller rather than zero the error out. This allows the integrator to increase to an appropriate value and decrease the size of the instantaneous change in magnitude when the inactive controller becomes active. First, the selected control signal to the fuel-metering valve, $W f C m d$ of Figure 4, is subtracted from the output of each individual controller, Wf Reg. The resulting difference is then amplified by an integral feedback gain $(I F B)$ and subtracted from the current limiter error, which is the input to the integrator. The $I F B$ is empirically tuned to provide adequate performance. Too high of an IFB gain results in the system responding like a proportional controller, or even resulting in negative integral gain which could destabilize the system, while an $I F B$ gain that is too low results in a traditional PI controller without $I W U P$. For C-MAPSS40k, the IFB is not gain scheduled, a constant value was found to perform 
sufficiently. For the controller that is currently active, the difference between the output of the MIN-MAX selector and the output of the controller is zero, and therefore the actual error is seen by the integrator. For the controllers that are not active, there will be a difference since the individual controller output will not be equal to the output of the $M I N-M A X$ selector. This difference reduces the error seen by the integrator term, thus preventing integral wind-up.

\subsection{Example Closed Loop Simulations}

With the control architecture and integral wind-up protection in place, the steady-state and transient controller PI gains must be tuned to ensure that the closed loop system can pass the FAA's Federal Aviation Regulation, Part 33, Section 33.73-Power or thrust response, from Reference 9:

The design and construction of the engine must enable an increase-

(a) From minimum to rated takeoff power or thrust with the maximum bleed air and power extraction to be permitted in an aircraft, without over temperature, surge, stall, or other detrimental factors occurring to the engine whenever the power control lever is moved from the minimum to the maximum position in not more than 1 second, except that the Administrator may allow additional time increments for different regimes of control operation requiring control scheduling; and

(b) From the fixed minimum flight idle power lever position when provided, or if not provided, from not more than 15 percent of the rated takeoff power or thrust available to 95 percent rated takeoff power or thrust in not over 5 seconds. The 5-second power or thrust response must occur from a stabilized static condition using only the bleed air and accessories loads necessary to run the engine. This takeoff rating is specified by the applicant and need not include thrust augmentation.

The FAR 33.73a test was conducted on C-MAPSS40k by running a step-change transient from minimum power to full power at Sea Level Static $(S L S)$ and observing the temperature, pressure, and stall margin outputs. For C-MAPSS40k this becomes:

- Throttle transient: 40 to 80.5 in one time step, occurring at $t=20 \mathrm{sec}$

- Simulation Time Step: $0.015 \mathrm{sec}$

- Altitude: $0 \mathrm{ft}$

- Mach Number: 0.0

- Delta Temperature Ambient: 0

- Power Extraction: $100 \mathrm{hp}$ — assumed to be maximum power extraction

- Customer Bleed: $4.0 \mathrm{lbm} / \mathrm{s}$ - assumed to be maximum customer bleed

The fan speed, core speed, T50, Ps3, and stall margin responses for C-MAPSS40k to the FAR 33.73a test are shown in Figure 8. Note that C-MAPSS40k has a sophisticated HPC stall margin calculation to take into account effects such as tip clearance and deterioration (Ref. 6); therefore a compressor that has a remaining stall margin greater than zero is considered stable. Figure 8 shows that the engine preserves adequate stall margin and that $T 50$ does not exceed a design limit $\left(1500^{\circ} \mathrm{R}\right.$ for C-MAPSS40k), which are both direct requirements of FAR 33.73. In addition, the rotor speeds do not increase beyond their limit.

The FAR $33.73 \mathrm{~b}$ test was conducted by running a step-change transient from approximately 15 percent full power thrust to full power at $S L S$ and observing the thrust response. The C-MAPSS40k inputs are the same as above except for the throttle transient, which is changed to:

- Throttle transient: 43 to 80.5 in one time step, transition occurring at $\mathrm{t}=20 \mathrm{sec}$ 
The thrust response and throttle command to the FAR 33.73b test are shown in Figure 9. C-MAPSS40k can respond from a static stabilized position less than 15 percent rated take-off power, shown as the green line in Figure 9, to 95 percent rated take-off power, shown as the red line in Figure 9, in $4.07 \mathrm{sec}$. These plots show that the C-MAPSS40k engine with the baseline controller meets the FAA requirements.
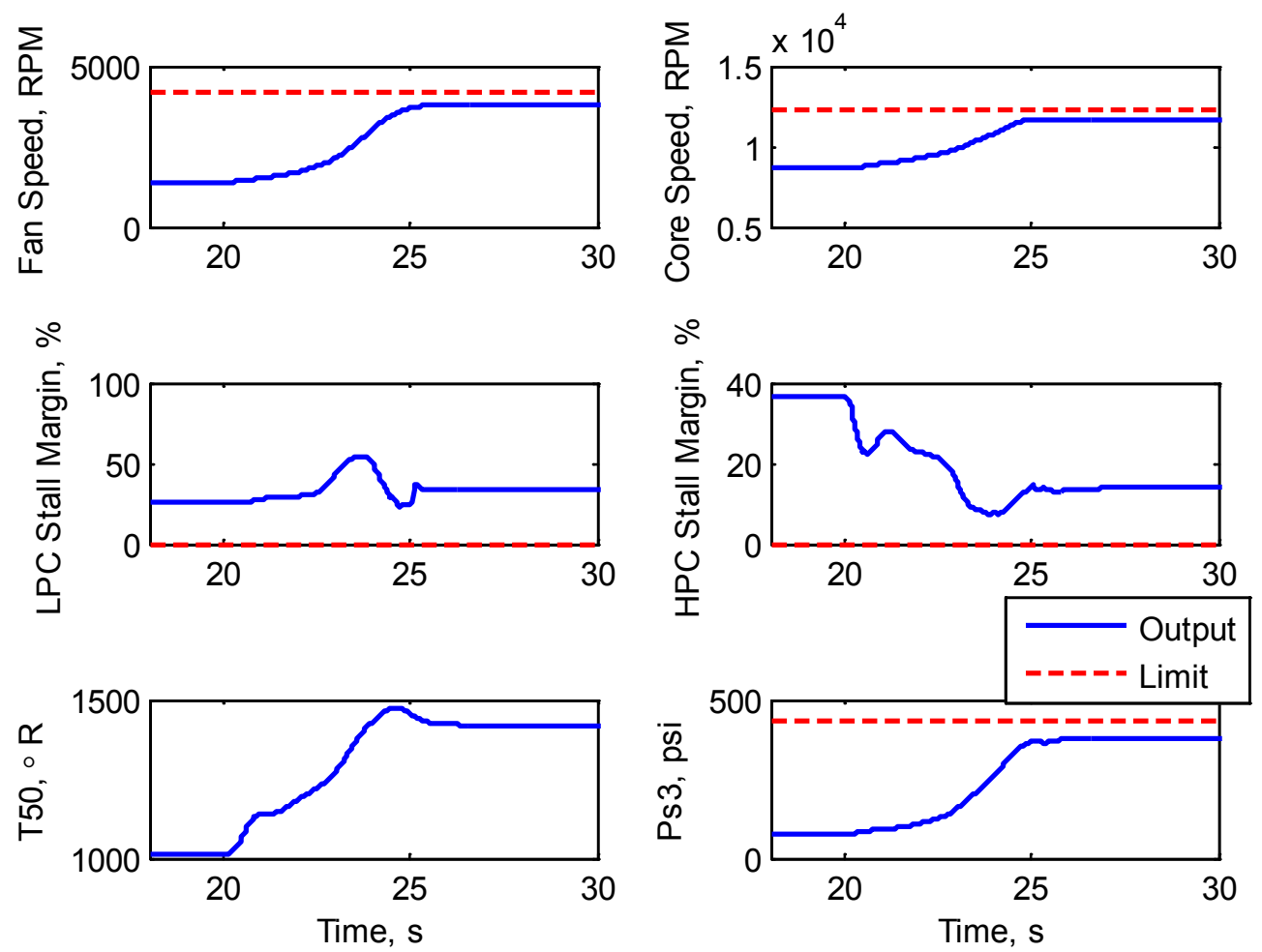

Figure 8.-C-MAPSS40k Response to FAR 33.73a.
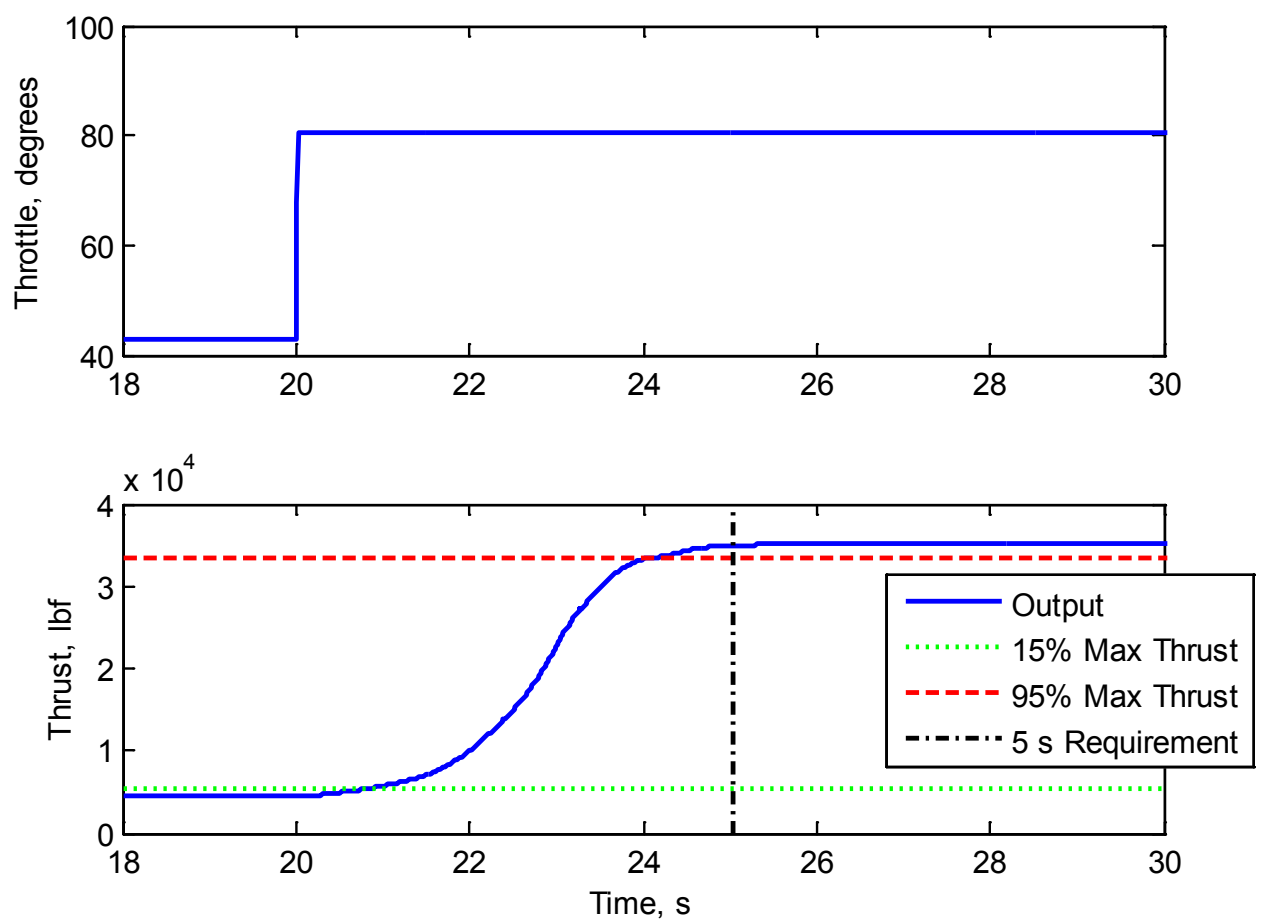

Figure 9.-C-MAPSS40k Response to FAR 33.73b. 


\section{Summary}

This paper provides the reader an explanation of the design process and choices made in the development of the baseline controller for C-MAPSS40k. The C-MAPSS40k controller contains an Engine Pressure Ratio and Fan Speed setpoint controller as well as a rotor speed limiter, a combustor pressure limiter, an acceleration schedule, and a ratio unit limiter. Each of these is a PI controller with integral wind-up protection. The control architecture applies a $M I N-M A X$ strategy to determine which control signal is sent to the engine's fuel metering valve. This paper also shows that the C-MAPSS40k simulation with the baseline controller passes the Federal Aviation Regulation on thrust response. While all results are specific to the C-MAPSS40k engine, this architecture and control design procedure are applicable to any commercial aircraft engine. 


\section{Appendix}

Figure 10 shows the architecture of the max fan speed limiter ( $N f$ max). The max fan speed is a constant value, as are the controller gains $(K p, K i$, and $I F B)$. The output of the max fan speed controller is WfNf_max. The max core speed and max Ps 3 controllers have the same basic architecture.

Figure 11 shows the minimum combustor pressure limiter $(P s 3 \mathrm{~min})$. The controller gains $(K p, K i$, and $I F B)$ are all constant values. The Ps 3 min setpoint, shown in Figure 11 as the output of the Ps 3 Min block, is scheduled based on altitude. In addition, if the aircraft is in flight there is a modification to the Ps $3 \mathrm{~min}$ setpoint based on altitude, shown in Figure 11 as the output of the Flight Idle block. The input WOW to the Flight Idle block (the weight on wheels indicator) determines if this adjustment should be applied by indicating whether the aircraft is on the ground. The other modification made to the Ps 3 min setpoint is based on the value of the customer bleed, shown in Figure 11 as Cust Bleed.

Figure 12 shows the acceleration schedule limiter. The max acceleration limit is determined from the acceleration schedule, shown in Figure 12 as the Ncdot Max block. The error is computed from the acceleration max (Ncdot Max) and the current acceleration calculated from the current core speed. The controller gains are constants in this limiter.

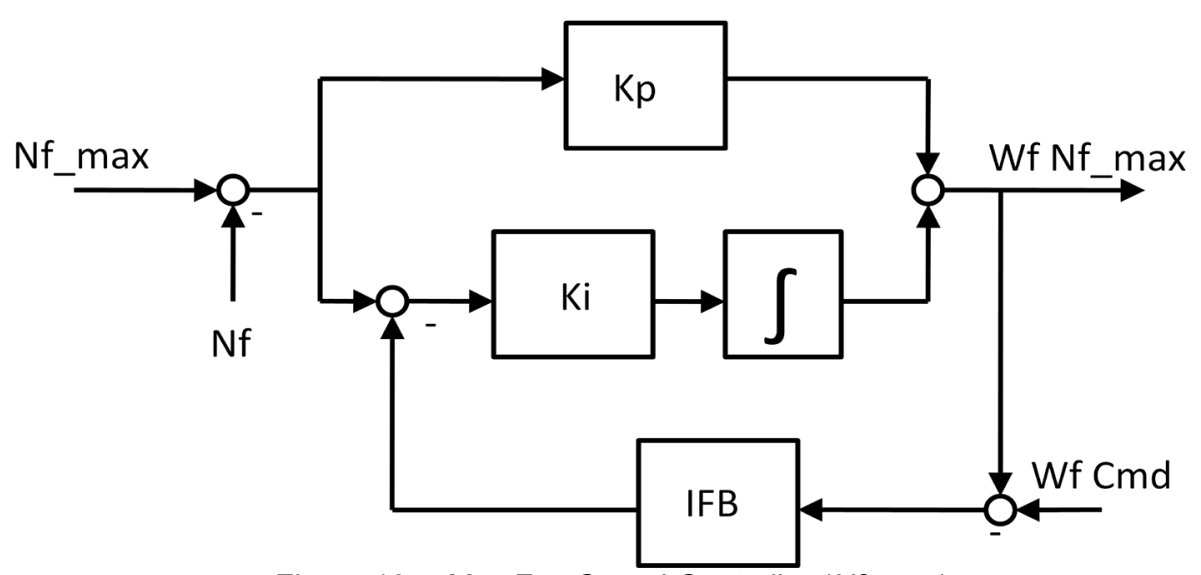

Figure 10.-Max Fan Speed Controller (Nf_max).

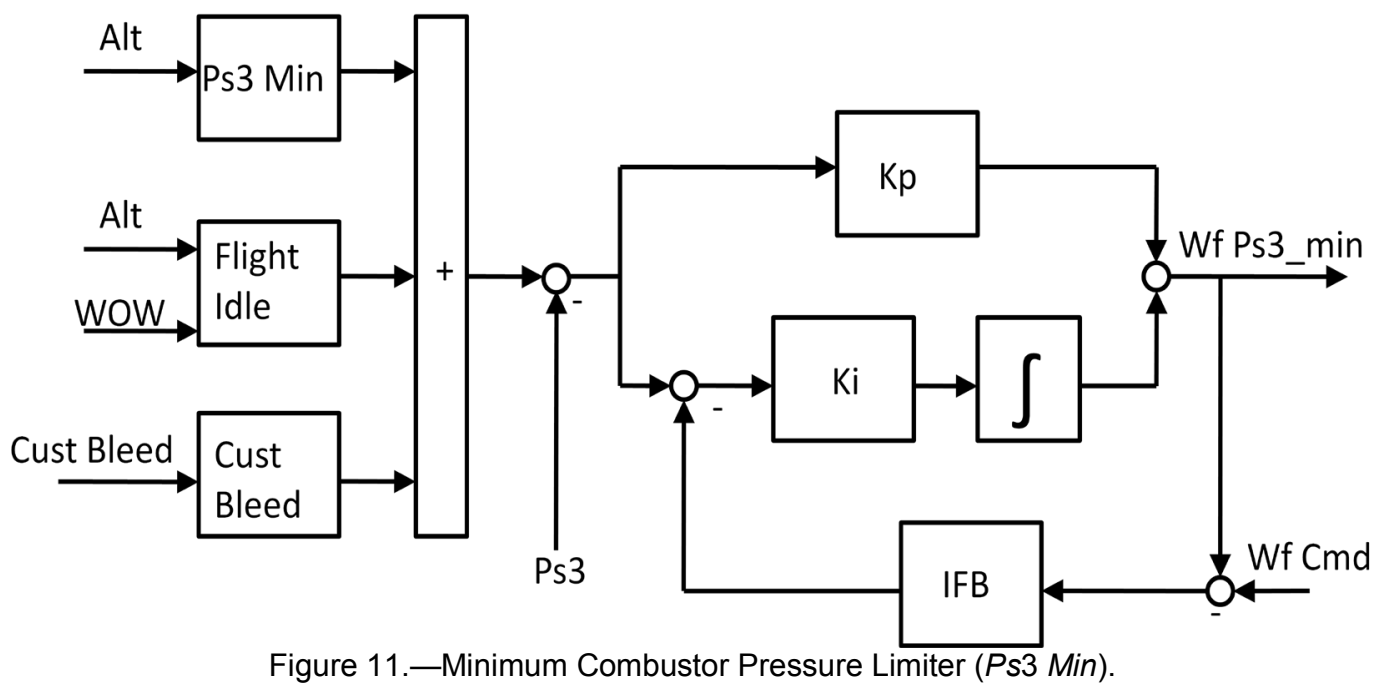


Figure 13 shows the Ratio Unit Limiter architecture. The ratio unit limit, WfQP3 in Figure 13, is a function of the current altitude. Multiplying the ratio unit ( $W f / P s 3)$ by the current static combustor pressure (Ps3) results in the minimum ratio unit fuel flow ( $W f R U_{-}$min).

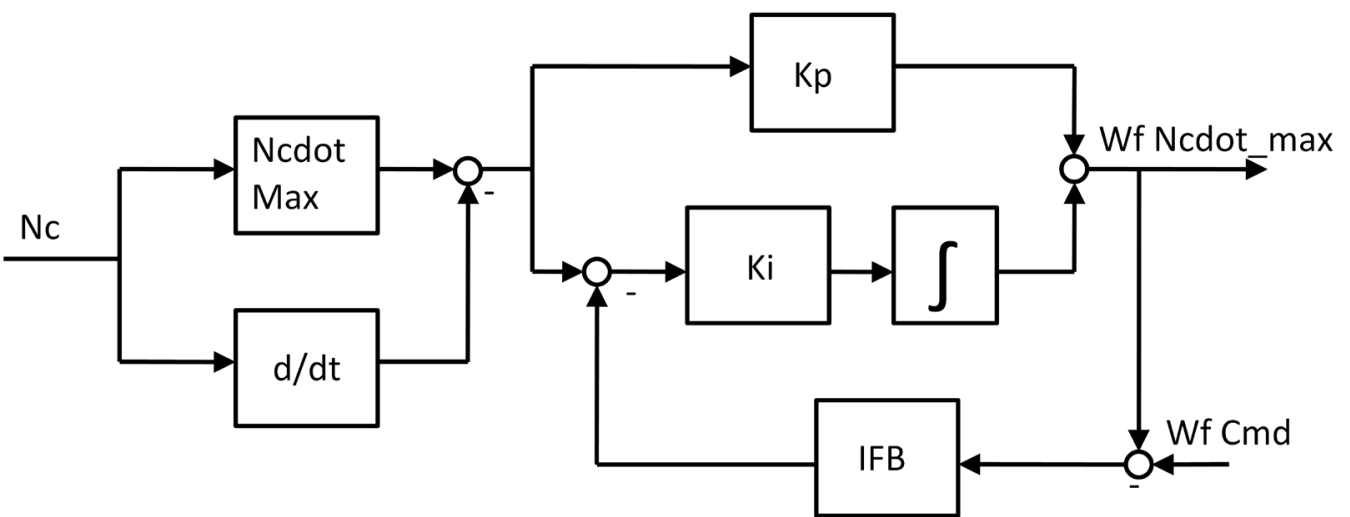

Figure 12.-Acceleration Schedule Limiter.

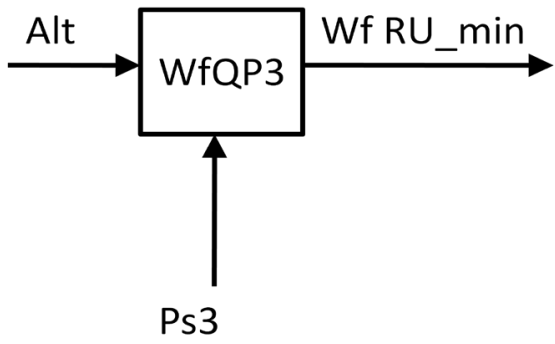

Figure 13.-Ratio Unit Limiter (Wf/Ps3). 


\section{References}

1. Jaw, L., and Mattingly, J.D., Aircraft Engine Controls: Design, System Analysis, and Health Monitoring, American Institute of Aeronautics and Astronautics, Inc., VA, 2009.

2. Mattingly, J.D., Heiser, W.H., and Pratt, D.T., Aircraft Engine Design, American Institute of Aeronautics, Inc, 2nd Edition, VA 2002.

3. Spang III, A.H., and Brown, H., "Control of Jet Engines," Control Engineering Practice, 8 March 1999, pp. 1043-1059.

4. DeCastro, J.A., Litt, J.S., and Frederick, D.K., "A Modular Aero-Propulsion System Simulation of a Large Commercial Aircraft Engine," AIAA-2008-4579, 44th AIAA/ASME/SAE/ASEE Joint Propulsion Conference \& Exhibit, Hartford, CT, July 21-23, 2008.

5. Martucci, A., and Volponi, A.J., "Fuzzy Fuel Flow Selection Logic for a Real Time Embedded Full Authority Digital Engine Control," Journal of Engineering for Gas Turbines and Power, Vol. 125, No. 4, pp. 909-916, 2003.

6. May, R.D., Csank, J., Lavelle, T.M., Litt, J.S., and Guo, T.H., "A High-Fidelity Simulation of a Generic Commercial Aircraft Engine and Controller," AIAA-2010-6630, AIAA 46th Joint Propulsion Conference and Exhibit, Nashville, TN, July 25-28, 2010.

7. D'Azzo, J.J., and Houpis, C.H., Linear Control Systems Analysis and Design, McGraw-Hill Book Company, 2nd Edition, 1991.

8. Martin, S., Wallace, I., and Bates, D.G., "Development and Validation of a Civil Aircraft Engine Simulation Model for Advanced Controller Design," Journal of Engineering for Gas Turbines and Power, Vol. 130, No. 5, 2008.

9. Federal Aviation Administration, "Title 14 of the Code of Federal Regulations," http://www.airweb.faa.gov/Regulatory_and_Guidance_Library/rgfar.nsf/MainFrame, accessed on June 2010 


\begin{tabular}{|c|c|c|}
\hline \multicolumn{2}{|c|}{ REPORT DOCUMENTATION PAGE } & $\begin{array}{l}\text { Form Approved } \\
\text { OMB No. 0704-0188 }\end{array}$ \\
\hline \multicolumn{3}{|c|}{ 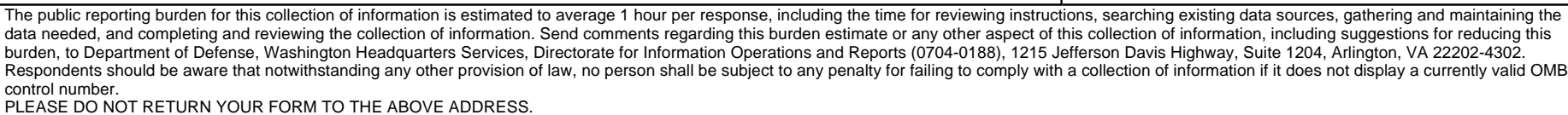 } \\
\hline $\begin{array}{l}\text { 1. REPORT DATE (DD-MM-YYYY) } \\
01-10-2010\end{array}$ & $\begin{array}{l}\text { 2. REPORT TYPE } \\
\text { Technical Memorandum }\end{array}$ & 3. DATES COVERED (From - To) \\
\hline \multirow{3}{*}{\multicolumn{2}{|c|}{$\begin{array}{l}\text { 4. TITLE AND SUBTITLE } \\
\text { Control Design for a Generic Commercial Aircraft Engine }\end{array}$}} & 5a. CONTRACT NUMBER \\
\hline & & 5b. GRANT NUMBER \\
\hline & & 5c. PROGRAM ELEMENT NUMBER \\
\hline \multirow{3}{*}{\multicolumn{2}{|c|}{$\begin{array}{l}\text { 6. AUTHOR(S) } \\
\text { Csank, Jeffrey; May, Ryan, D.; Litt, Jonathan, S.; Guo, Ten-Huei }\end{array}$}} & 5d. PROJECT NUMBER \\
\hline & & 5e. TASK NUMBER \\
\hline & & $\begin{array}{l}\text { 5f. WORK UNIT NUMBER } \\
\text { WBS 457280.02.07.03.03.01 }\end{array}$ \\
\hline \multicolumn{2}{|c|}{$\begin{array}{l}\text { 7. PERFORMING ORGANIZATION NAME(S) AND ADDRESS(ES) } \\
\text { National Aeronautics and Space Administration } \\
\text { John H. Glenn Research Center at Lewis Field } \\
\text { Cleveland, Ohio 44135-3191 }\end{array}$} & $\begin{array}{l}\text { 8. PERFORMING ORGANIZATION } \\
\text { REPORT NUMBER } \\
\text { E-17443 }\end{array}$ \\
\hline \multirow{2}{*}{\multicolumn{2}{|c|}{$\begin{array}{l}\text { 9. SPONSORING/MONITORING AGENCY NAME(S) AND ADDRESS(ES) } \\
\text { National Aeronautics and Space Administration } \\
\text { Washington, DC 20546-0001 }\end{array}$}} & $\begin{array}{l}\text { 10. SPONSORING/MONITOR'S } \\
\text { ACRONYM(S) } \\
\text { NASA }\end{array}$ \\
\hline & & $\begin{array}{l}\text { 11. SPONSORING/MONITORING } \\
\text { REPORT NUMBER } \\
\text { NASA/TM-2010-216811 }\end{array}$ \\
\hline \multicolumn{3}{|c|}{$\begin{array}{l}\text { 12. DISTRIBUTIONIAVAILABILITY STATEMENT } \\
\text { Unclassified-Unlimited } \\
\text { Subject Category: } 07 \\
\text { Available electronically at http://gltrs.grc.nasa.gov } \\
\text { This publication is available from the NASA Center for AeroSpace Information, 443-757-5802 }\end{array}$} \\
\hline
\end{tabular}

\section{SUPPLEMENTARY NOTES}

\section{ABSTRACT}

This paper describes the control algorithms and control design process for a generic commercial aircraft engine simulation of a 40,000 lb thrust class, two spool, high bypass ratio turbofan engine. The aircraft engine is a complex nonlinear system designed to operate over an extreme range of environmental conditions, at temperatures from approximately -60 to $120+{ }^{\circ} \mathrm{F}$, and at altitudes from below sea level to $40,000 \mathrm{ft}$, posing multiple control design constraints. The objective of this paper is to provide the reader an overview of the control design process, design considerations, and justifications as to why the particular architecture and limits have been chosen. The controller architecture contains a gain-scheduled Proportional Integral controller along with logic to protect the aircraft engine from exceeding any limits. Simulation results illustrate that the closed loop system meets the Federal Aviation Administration's thrust response requirements.

\section{SUBJECT TERMS}

Turbofan engine control

\begin{tabular}{|c|c|c|c|c|c|}
\hline \multicolumn{3}{|c|}{ 16. SECURITY CLASSIFICATION OF: } & \multirow{2}{*}{$\begin{array}{l}\text { 17. LIMITATION OF } \\
\text { ABSTRACT } \\
\text { UU }\end{array}$} & \multirow{2}{*}{$\begin{array}{l}\text { 18. NUMBER } \\
\text { OF } \\
\text { PAGES } \\
23\end{array}$} & \multirow{2}{*}{$\begin{array}{l}\text { 19a. NAME OF RESPONSIBLE PERSON } \\
\text { STI Help Desk (email:help@sti.nasa.gov) } \\
\text { 19b. TELEPHONE NUMBER (include area code) } \\
\text { 443-757-5802 }\end{array}$} \\
\hline $\begin{array}{l}\text { a. REPORT } \\
U\end{array}$ & $\begin{array}{l}\text { b. ABSTRACT } \\
U\end{array}$ & $\begin{array}{l}\text { c. THIS } \\
\text { PAGE } \\
\text { U }\end{array}$ & & & \\
\hline
\end{tabular}



